\title{
Assessing the influence of conflict on the dynamics of sex work and the HIV and HCV epidemics in Ukraine: protocol for an observational, ethnographic, and mathematical modeling study
}

Marissa Becker ${ }^{1,2^{*}}$ D , Olga Balakireva ${ }^{3}$, Daria Pavlova ${ }^{3}$, Shajy Isac ${ }^{1,4}$, Eve Cheuk ${ }^{1}$, Elizabeth Roberts ${ }^{5}$, Evelyn Forget ${ }^{2}$, Huiting $\mathrm{Ma}^{6}$, Lisa Lazarus ${ }^{1}$, Paul Sandstrom7, James Blanchard ${ }^{1}$, Sharmistha Mishra ${ }^{6}$, Rob Lorway ${ }^{1}$,

Michael Pickles ${ }^{1}$ and on behalf of the Dynamics Study Team

\begin{abstract}
Background: Armed conflict erupted in eastern Ukraine in 2014 and still continues. This conflict has resulted in an intensification of poverty, displacement and migration, and has weakened the local health system. Ukraine has some of the highest rates of HIV and Hepatitis C (HCV) in Europe. Whether and how the current conflict, and its consequences, will lead to changes in the HIV and HCV epidemic in Ukraine is unclear. Our study aims to characterize how the armed conflict in eastern Ukraine and its consequences influence the pattern, practice, and experience of sex work and how this affects HIV and HCV rates among female sex workers (FSWs) and their clients.

Methods: We are implementing a 5-year mixed methods study in Dnipro, eastern Ukraine. Serial mapping and size estimation of FSWs and clients will be conducted followed by bio-behavioral cross-sectional surveys among FSWs and their clients. The qualitative component of the study will include in-depth interviews with FSWs and other key stakeholders and participant diaries will be implemented with FSWs. We will also conduct an archival review over the course of the project. Finally, we will use these data to develop and structure a mathematical model with which to estimate the potential influence of changes due to conflict on the trajectory of HIV and HCV epidemics among FSW and clients.

Discussion: The limited data that exists on the effect of conflict on disease transmission provides mixed results. Our study will provide rigorous, timely and context-specific data on HIV and HCV transmission in the setting of conflict. This information can be used to inform the design and delivery of HIV and HCV prevention and care services.
\end{abstract}

Keywords: HIV, HCV, Ukraine, Sex work, Conflict

\footnotetext{
*Correspondence: Marissa.becker@umanitoba.ca;

marissa.becker@umanitoba.ca

${ }^{1}$ Centre for Global Public Health, Rady Faculty of Health Sciences, University

of Manitoba, R070 Med Rehab Bldg, 771 McDermot Avenue, Winnipeg,

Manitoba R3E OT6, Canada

${ }^{2}$ Department of Community Health Sciences, University of Manitoba, S113 -

750 Bannatyne Avenue, Winnipeg, Manitoba R3E OW3, Canada

Full list of author information is available at the end of the article
}

(c) The Author(s). 2019 Open Access This article is distributed under the terms of the Creative Commons Attribution 4.0 International License (http://creativecommons.org/licenses/by/4.0/) which permits unrestricted use, distribution, and reproduction in any medium, provided you give appropriate credit to the original author(s) and the source, provide a link to the Creative Commons license, and indicate if changes were made. The Creative Commons Public Domain Dedication waiver (http://creativecommons.org/publicdomain/zero/1.0/) applies to the data made available in this article, unless otherwise stated. 


\section{Background}

In 2014, an armed conflict erupted, and still continues, in Ukraine. The Crimean Peninsula was annexed and the eastern regions of Donetsk and Luhansk of Ukraine were attacked [1]. This conflict has led to the internal displacement of more than 1.6 million people and has resulted in the disruption of water, sanitation, and medical services [1-3]. With a weakening public health system in the occupied and eastern regions and movement of internally displaced people into the mainland, there are growing concerns about the potential rise in HIV and Hepatitis C (HCV) in Ukraine [4-9].

By 2016, Ukraine already had the second largest HIV epidemic in Eastern Europe and Central Asia with 240,000 people living with HIV (PLHIV) and 13,000 new HIV infections for an incidence among adults 15-49 years of 0.55 per 1000 population $[10,11]$. Ukraine also has some of the highest rates of $\mathrm{HCV}$, with a prevalence of $12 \%$ in the general population [12]. While overall there has not been an increase in HIV incidence since the start of the conflict in 2014, some areas have seen HIV incidence increase by up to $36 \%$ from 2014 to 2016 [7, 13, 14]. In general, the HIV epidemic in Ukraine is concentrated in the east where the armed conflict is most severe [15]. Among registered PLHIV, 50\% live in just three regions of eastern Ukraine (Donetsk, Dnipropetrovsk, and Odessa) with an HIV prevalence rate of 736 per 100,000 population in Dnipropetrovsk in 2014 [10, 16]. Given its close proximity of $200 \mathrm{~km}$ from the center of conflict in Donetsk, the city of Dnipro in Dnipropetrovsk has been one of the main destinations for internally displaced persons and members of the frontline forces since the beginning of conflict [17]. Vasylyeva et al. recently demonstrated that HIV viral lineages have moved from Donetsk and Luhansk in eastern Ukraine to other parts of Ukraine, corresponding to the movement of people displaced during the armed conflict [7].

Conflict creates "complex emergencies" [18, 19] with consequences which include an intensification of poverty, displacement and migration, and weakened health systems [4, 5, 19-21]. Despite our understanding of the linkage between poverty [22-24], violence [25, 26], and migration with HIV $[27,28]$, there are insufficient data to conclude that conflict leads to higher rates of HIV $[20,21]$. Two systematic reviews found no evidence to suggest that there was an increase in HIV during conflict $[20,21]$. However, the authors caution that the association between conflict and HIV is complex and that this association needs to be examined in context.

In effort to understand these complex relationships further, Mock et al. developed a framework on conflict and HIV which uses a social ecology approach and examines the interactions of the multiple causes of an HIV epidemic, at the individual, household and community level, and emphasizes the dynamic nature of these factors [29]. This framework is useful for better understanding the interrelationship between conflict and HIV and illustrates how many of the factors present in Ukraine right now, such as migration, increased interaction among military and civilians, increased population mixing, fragmentation of families, and increased levels of commercial and casual sex, are some of the factors which have the potential to lead to an increase in HIV [8, 29-31].

.In Ukraine, there are an estimated 80,100 female sex workers (FSWs) with an HIV prevalence of 5.2\% in 2016 $[11,14,32]$. Very little data exist on whether sex work changes during times of conflict. Elmes et al. began to address this question in Zimbabwe following the economic upheaval in the country and demonstrated that the changing economic conditions there resulted in women exchanging sex in less formal settings and engaging in riskier transactions [33].

To our knowledge, no data exists on the influence of conflict on HIV in Eastern Europe, nor on the influence of conflict on sex work in the region. Our study aims to characterize how the armed conflict in eastern Ukraine and its consequences influence the pattern, practice, and experience of sex work and how this affects HIV and HCV rates among FSWs and their clients.

\section{Methods}

\section{Study setting}

The study will take place in Dnipro, an industrial city in eastern Ukraine, with a population of approximately 1 million [34]. Dnipro was chosen for this study due to its proximity to the center of the conflict $(200 \mathrm{~km})$, its HIV prevalence among FSWs (6.7\%) [35], and the size of the sex work population [1087 (range 817-1357)] [36]. The study will be conducted in partnership with the Ukrainian Institute for Social Research after Oleksandr Yaremenko (UISR) and The Center for Public Health of the Ministry of Health in Ukraine.

\section{Study hypothesis and objectives}

We hypothesize that conflict and its consequences are associated with changes in the organization of sex work (more people selling and buying sex), sex work patterns (earlier age of entry into sex work), and the practice and experience of sex work (higher turnover, more clients, more injection drug use, and more violence), leading to increased HIV and HCV transmission among FSWs and clients.

Our overarching objectives are:

i) To characterize how conflict and its consequences influence the organization (where and how sex work is managed, FSW/client population size), pattern (age distribution, sex work duration), 
practice and experience of sex work (client volume, drug use, violence), uptake of health and social services and the HIV and HCV prevalence among FSWs and clients in Dnipro.

ii) To estimate the influence of political conflict and its consequences via changes in sex work on HIV and $\mathrm{HCV}$ transmission among FSWs and clients.

\section{Study design}

This study is a serial cross-sectional biological and behavioural survey and it does not offer or assign participants to any health-related interventions. We will use a mixed methods approach with both quantitative and qualitative methodologies to address these objectives (Fig. 1). These methods include: i) mapping; ii) bio-behavioural surveys; iii) in-depth interviews, participant diaries, and archival review; and iv) mathematical modelling.

Serial mapping and estimation of FSW and clients will be conducted 3 times at 2-year intervals to measure changes in the organization of sex work. Serial bio-behavioral crosssectional surveys will quantify population-based changes in the pattern, practice, and experiences of sex work; and uptake of health and social services; and HIV/HCV prevalence. The qualitative component of the study, including the in-depth interviews, participant diaries, and archival review will explore the influence of conflict at the individual level and how this changes over time. Finally, we will use these data to develop and structure a mathematical model with which to estimate the potential influence of changes due to conflict on the trajectory of HIV and HCV epidemics among FSW and clients.

\section{Mapping and enumeration}

First, UISR will conduct geographic mapping [37] of venues associated with sex work ('hotspots' defined as locations where FSWs solicit and/or have sex with clients) and characterize the attributes of hotspots. Examples of these attributes include whether the spot is considered safe, whether it is a spot where injection drug use occurs, or where people who inject drugs congregate. We will simultaneously estimate the FSW and client population size within hotspots and by typology of

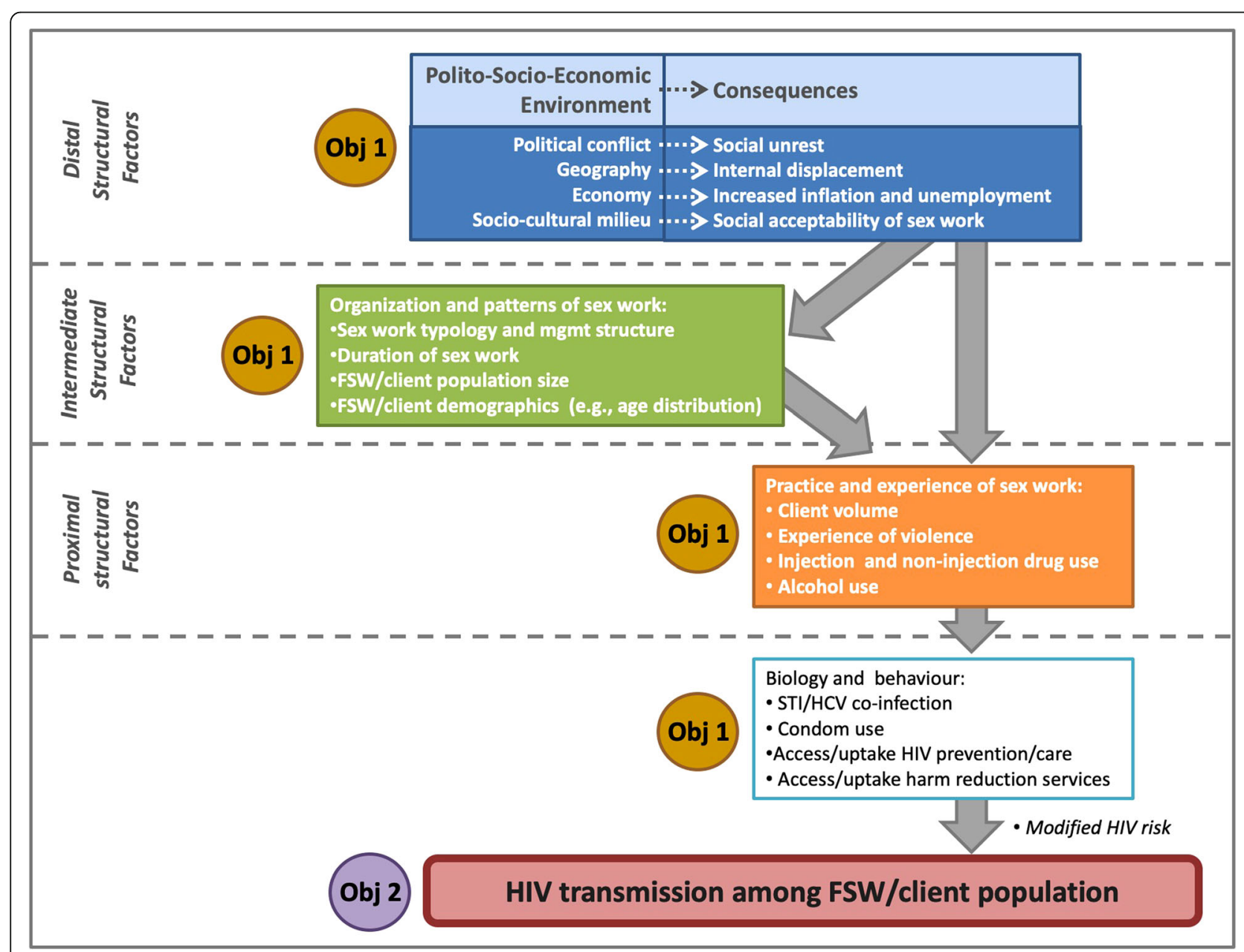

Fig. 1 Conceptual Framework for HIV transmission 
sex work in Dnipro. Our team has extensive experience with geographic mapping and key population size estimation [37-41]. FSW and client population size estimates by hotspot will comprise the sampling frame for the cross-sectional bio-behavioral surveys among FSWs and clients [38]. Sampling of FSWs and clients will follow a two stage sampling design, where in the first stage a representative sample of hotspots will be selected, followed in the second stage by randomly sampling FSWs or clients from each selected hotspot. To generate a representative sample of hotspots we will use a stratified random sampling, where the hotspots are selected randomly after stratifying the hotspots by administrative division and type of hotspot. The sample size for each selected hotspot is proportional to the size of the respective population estimated in the hotspot from the mapping. Recruitment of clients will be based on time-location sampling.

\section{Serial cross-sectional bio-Behavioural surveys}

We will conduct three rounds of a cross-sectional bio-behavioral survey among FSWs and clients at three time points approximately 2 years apart (Fig. 2). Each round of survey is anticipated to take 3 months.

FSWs age 14 years or older who self-identify as currently engaged in sex work are eligible to participate. Eligible clients will be men aged 18 or over who have ever purchased sex.

Recruitment of participants (FSWs and clients) will be facilitated by outreach workers who will act as mobilizers at the selected hotspots. These mobilizers will visit the selected hotspots and explain the study. If a potential participant expresses interest in the study, s/he will be escorted to a mobile van in the vicinity where $\mathrm{s} / \mathrm{he}$ will meet with a trained interviewer. These interviewers will obtain written informed consent followed by faceto-face administration of a structured questionnaire in the local language (Russian). Survey questions, based on the Integrated Biological and Behavioural Survey (IBBS) Guidelines and our past work [42], have been piloted and locally validated. Participants will be asked about basic socio-demographic characteristics including age, educational level, and marital status; vulnerabilities

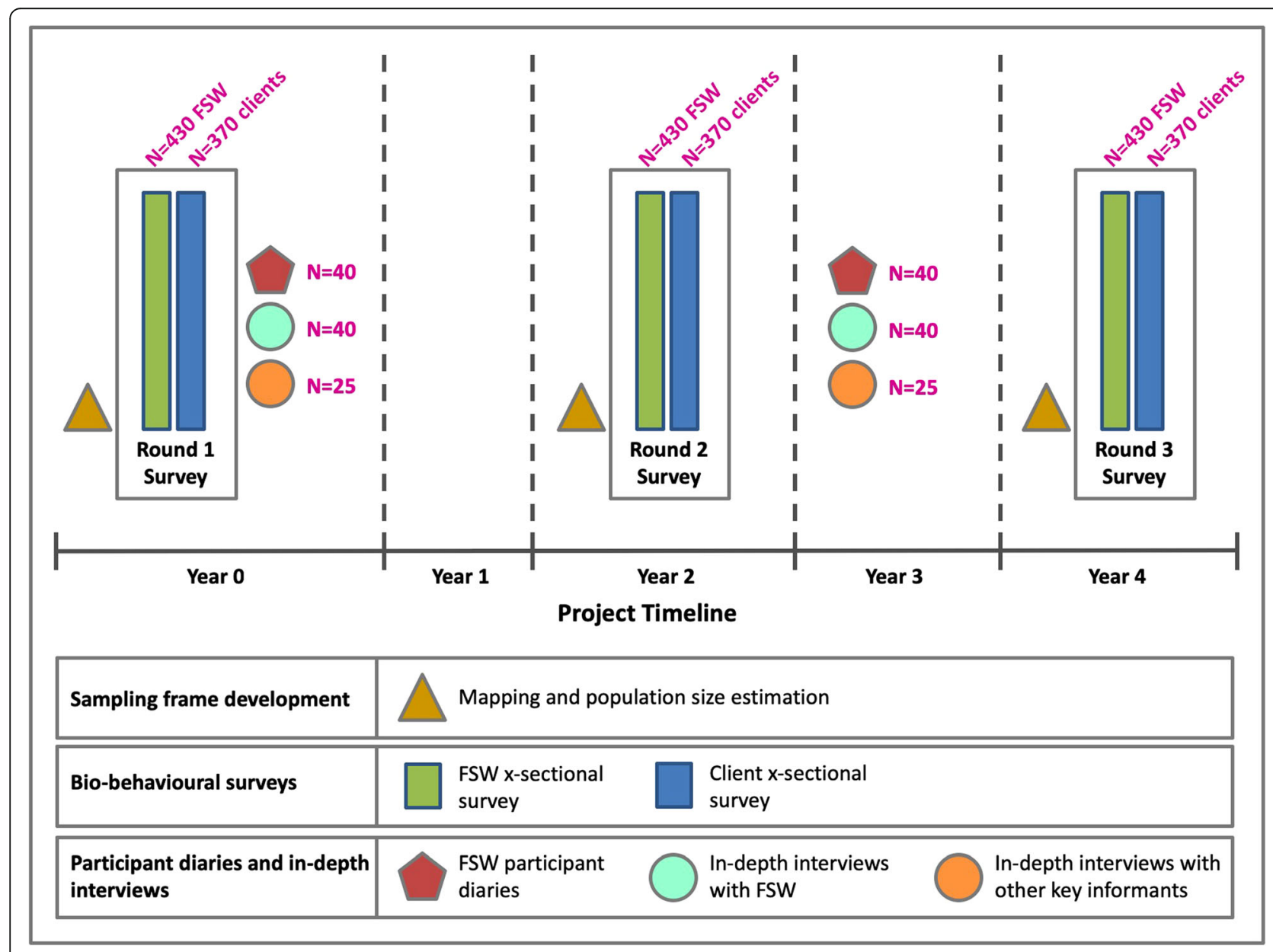

Fig. 2 Study design and methodology 
and protective factors related to HIV and HCV risk, including partner volume, condom use, and injection drug use; and structural factors including experience of violence, alcohol consumption, and access to programs and clinical services. Questions specific to the conflict for FSWs include: interactions with military, migration resulting from conflict, economic impact from conflict, and entry into sex work as a result of the conflict.

The FSW questionnaire is anticipated to take $45 \mathrm{~min}$ to complete. The client questionnaire is anticipated to take 25 min to complete.

Following administration of the questionnaire, consenting participants will receive HIV and HCV rapid testing conducted by a medical worker certified by the Dnipropetrovsk Oblast AIDS Centre. Pre- and post-test counselling will be provided according to national guidelines [43, 44]. Participants can choose not to receive testing results. All participants will be linked with local HIV and HCV prevention programs and participants who test positive will be referred to treatment services. A dried blood spot sample (DBS) will also be collected and sent to the National HIV and Retrovirology Laboratories, Winnipeg, Canada for serological confirmation and $\mathrm{HIV} / \mathrm{HCV}$ viral sequencing analysis, if consent is given. Participants will be able to access their results of the reference DBS HIV and HCV serological test results through a toll-free hotline number established for this study. This hotline was created as a result of request voiced by the community and will be managed by the Dnipropetrovsk Oblast AIDS Centre.

\section{Sample size for the serial cross-sectional bio-behavioral surveys}

The target sample size for each round of surveys is 560 FSWs and 370 clients based on $80 \%$ power and a $5 \%$ alpha error in two outcomes: experience of physical violence among FSW during encounters with clients (current level 42\%) [32, 35] and injecting drug use among clients (current level 26\%) [45]. This will also account for a $10 \%$ ineligibility, observed in our previous work in Dnipro. The sample size accounts for a design effect of 1.5 via the cluster-based sampling.

\section{In-depth interviews, diaries, and archival review}

Qualitative data will be collected at two time points approximately 3 years apart. Three different qualitative methodologies will be used: i) in-depth interviews, ii) participant diaries, and iii) archival review.

\section{In-depth interviews and participant diaries}

Forty FSWs will be recruited through two main routes: i) from survey participants who have expressed interest in taking part in the qualitative component; and ii) purposively recruited through networks of "social workers" (a type of local community health worker) with whom
FSWs have established rapport and trust. In each wave of data collection, participants will be interviewed every 2 weeks over a period of 2 months. Interviewers will be affiliated with UISR and will receive training on the semi-structured interview guide and qualitative interviewing techniques. Participants will be invited to also take part in diary writing -4 entries per week throughout the course of their interview participation. The first interview of this qualitative series will elicit participants' perceptions in the following areas: of the sex trade generally; their experience with clients, coworkers, and police; migration; their health care needs and access; and how these aspects of their lives have been influenced by conflict. Two weeks later during the second interview, discussion will center around topics to be covered in the diaries: 1) work life, income, and trying to make ends meet; 2) specific interactions with clients and other people in the industry in the past 2 weeks that carried important meaning to the participants; 3) any experiences of accessing health and social services; and 4) interactions in their personal and/or family lives, including those with partners and children. During the second interview, participants will be asked if they would reflect and expand on topics discussed in the first interview. Discussion during the third and fourth (exit) interviews will revolve around, and delve more deeply into, the impressions and events recorded by the participants in their diaries. Each interview is expected to last approximately 1 hour and will be audio recorded. Following the transcription of diary entries, participants will have the opportunity to have their diaries returned to them.

Additional in-depth interviews will be conducted with key informants: brothel managers or pimps, service providers (e.g., medical workers/clinicians and social/outreach workers who provide services to FSWs), law enforcement officials (e.g., both national and regional levels that deal with issues related to sex work, human trafficking, and human rights) and other national stakeholders (e.g., representatives from Ministry of Health and Ministry of Internal Affairs, NGOs that work with issues related to HIV and human rights). Participants for key informant interviews will be purposively sampled. Social workers will assist in recruiting key informants associated with sex work such as brothel managers and pimps. Service providers and national stakeholders will be recruited through existing relationships held by the study team. These interviews will aim at gathering information on the social, political, and policy environments surrounding sex work. Twenty-five interviews will be conducted. Interviews are expected to last approximately 1 hour and will be audio recorded.

\section{Archival review}

Data from the qualitative strand will be triangulated with primary archival data, such as newspapers, parliamentary 
debate transcripts, and municipal records from the State Statistics Service of Ukraine, the Ministry of Health of Ukraine, and country-level behavioural surveys. This data will establish the social, geopolitical, and economic milieu in which the experience of individual FSW/client is embedded as conflict continues to evolve.

\section{Analysis \\ Quantitative data analysis}

Changes in the organization of sex work (ecological-level outcomes): We will use the serial mapping data to identify variability - at the ecological level - in the organization of sex work (defined as distribution of sex work typologies) and absolute and relative population size of FSWs and of clients between the survey time-points.

Changes in the pattern and practice of sex work: We will examine changes in the pattern and practice of sex work by using both ecological and individual level variables. This data will be obtained from the bio-behavioural survey as well as publicly available data. The exposure variables are as follows:

Ecological exposure variables include established measures of conflict-related factors (e.g, numbers of troops in DNK and battlefield deaths), internal displacement, inflation and unemployment rate, in the year of each survey [20, 21, 46]. Individual-level exposure variables include known consequences of political conflict, such as household income, recent unemployment, and migration status, which will be collected from the study survey $[46,47]$.

Outcome variables for the analysis include the following:

Organization of sex work (ecological outcomes): sex work typology (place/method of solicitation); FSW/ client population size. The pattern of sex work will be examined by looking at the following individual level outcomes: age of entry into sex work, duration in sex work. The practice of sex work will be examined with the following individual level outcomes: FSW-reported client volume; drug use; FSW experience of different types of violence (in the preceding month).

We will examine socio-demographics, individual-level exposures, and outcomes using measures of central tendency, and compare outcomes between rounds using parametric and non-parametric tests of difference, with $p<0.05$ for significance.

Multivariate logistic regression will be used for dichotomous outcomes, linear regression for continuous outcomes, and Poisson regression for count outcomes. Multi-level models will be used to include both ecological and individual outcomes. Each outcome will be analyzed separately for FSWs and clients. Only ecological outcomes will be used to examine sex work organization. All outcomes will be tested as potential covariates for the $\mathrm{HIV} / \mathrm{HCV}$ prevalence outcomes. Adjustments will be made for age and a proximate determinant framework of nested models will be used to isolate the individual-level mediators of $\mathrm{HIV} / \mathrm{HCV}$ prevalence.

\section{Qualitative data analysis}

All qualitative data will undergo interpretivist analysis after being transcribed and translated into English. The data will be analyzed using an idiographic approach. Interview recordings and diaries will be examined individually and notes will be made. Inductive thematic analysis will use these notes to construct conceptual themes from the qualitative data and the archival texts. The data will then be imported into NVivo12 Plus software to complete content analysis. This software will examine the frequency of themes, the characteristics of each theme, and will sort themes into meta-themes/sub-themes. Aggregated data patterns will be used to demonstrate change over time. Data from the interviews and diaries will be triangulated with the archival data.

\section{Mathematical modeling}

A mathematical model of HIV and HCV transmission among FSWs and their clients will be developed. The model structure will capture the influences identified through the cross-sectional surveys, in-depth interviews, and participant diaries and thus will reflect the empirical understanding of how conflict may be changing sex work and associated HIV and HCV risk in Dnipro. The model will incorporate the effects of structural factors both through modifying parameters linked to state-transitions, and through stratifying by exposure to the structural factor itself when the dynamics of exposure is important. These structural factors will influence risk and protective behaviours that in turn modify the individual-level probability of HIV/HCV susceptibility and/or infectivity. The model will be parameterized and calibrated using data both from the current study and the earlier Transitions study also carried out in Dnipro [36], as well as prior cross-sectional bio-behavioural surveys among FSWs [35].

The model will quantify the impact of changes in the organization, pattern and practice of sex work on the HIV/HCV epidemics among FSWs and clients from 2014 (start of the conflict) to 2022. To do this, we will use counterfactual scenarios where all parameters are as in the full model, except for key associations in the proposed causal pathway which are 'turned off'. Impact is then calculated as the difference in cumulative infections between the full and counterfactual model projections. We will then project how the long-term, future epidemic trajectory has changed due to the conflict, using 
estimates from the full model over the subsequent 10 years. Finally, the model will be used to understand which conflict-mediated changes may have had the greatest epidemic impact, with a view to informing and improving $\mathrm{HIV} / \mathrm{HCV}$ prevention and treatment programs.

\section{Data storage, security, and confidentiality}

The consent forms will be stored separately from other data in a locked and secure cabinet in Kiev in the UISR office. Study forms and surveys will be transferred to Kiev where they will be kept in a secure cabinet in the UISR office. Only the Principal Investigators and Co-Investigators have access to the completed forms. Each participant is given a unique alphanumeric code for identification. All data and biological samples are associated with this Study ID only. Information is entered into a database in the UISR office in Kiev and is then uploaded to a secure server at the Centre for Global Public Health (CGPH), University of Manitoba, Canada. Interview recordings and translated interview transcripts and diaries will also be uploaded to the server from the UISR office. The CGPH network is protected by an electronic firewall and a virtual private network (VPN) double password login system. Access to the data on the secure server is granted only to study investigators and the University of Manitoba Research Ethics Board (REB). Internet access, personal e-mail access, CD writers, and USB drives are prohibited in the data laboratory. Remote access to the data server may be made available to those approved on the study team. However, all data analysis will be performed in the virtual interface and no data will be allowed to be exported from the virtual environment.

\section{Ethical approval}

Ethical approval was obtained from the Human Research Ethics Board at the University of Manitoba [HS20653(H2017:097)], Canada, the Ethical Review Committee of the Sociological Association of Ukraine, and the Committee on Medical Ethics of the L. Gromashevsky Institute of Epidemiology and Infectious Diseases at the National Academy of Medical Sciences of Ukraine.

\section{Knowledge translation}

We have partnered with two local community-based organizations in Dnipro that provide services to people who use drugs and sex workers so that study outcomes may lead to tangible action in policy and programs at the local level, Virtus and Road to Life. In addition, we have also partnered with the Dnipro Oblast AIDS Centre for support on HIV and HCV testing and care. At the national level, key partners include UISR, Alliance for Public Health and Center for Public Health of the Ministry of Health in Ukraine. This study will follow an integrated knowledge translation model [48] to ensure an iterative process for knowledge uptake and the refinement of program-driven research questions. During the course of the study, regular video/web conferences, in-country joint dissemination, and consultative program design meetings will be held to share study findings, refine study tools, and foster discussion around the significance and context of the findings. We will create briefing reports for national and international decision-makers. Incoming data will be integrated throughout the study to inform changes in the questionnaires and interview guides.

\section{Discussion}

There is a strong belief that conflict increases the spread of HIV and HCV [49]. Conflict affects public health systems, impeding treatment and prevention activities and posing a major challenge to accurate epidemic monitoring; it can also lead to increased displacement and migration and is likely to affect the nature and practice of sex work, all of which will modify sexual networks. However, to date what little data there is to quantify the effect of conflict on disease transmission presents a mixed picture. Two studies in sub-Saharan Africa found no significant overall effect of conflict [20,21], although the lack of observed effect may be due to the difficulty in collecting representative data samples at multiple time-points during conflict, including amongst groups most affected by the conflict, and hence any such result requires careful interpretation [20]. We need a better understanding of whether, and how, conflict affects the HIV epidemic, to be able to more effectively adapt and supplement prevention and treatment efforts during conflicts.

In this study we will investigate how conflict and its consequences impact the HIV and HCV epidemics in Dnipro, a city close to the conflict region in Ukraine. We will use a mixed methods approach to gain a broad understanding of how conflict influences the organization, pattern, and practice of sex work, as well as how the interplay of these factors determines the trajectory of the. The quantitative findings will be complemented and enriched by the qualitative work that will construct a narrative of health and conflict from social, geopolitical, and economic perspectives, serving as the backdrop for the unfolding $\mathrm{HIV} / \mathrm{HCV}$ epidemics and public health response. The proposed qualitative work will also generate rich depictions of the lived experiences of sex workers and the effect that conflict has on their lives. Mathematical modelling will allow us to project possible trajectories of the HIV and $\mathrm{HCV}$ epidemics as the conflict evolves, and provide quantitative estimates of how conflict has impacted the HIV and HCV epidemics.

\section{Limitations}

This study has several limitations. Firstly, all behavioral data is self-reported and collected face to face, and thus 
social desirability bias may lead to under-reporting of certain risk behaviors. Survey questionnaires have been designed to reduce the magnitude of this bias as will the inclusion of skilled interviewers. Secondly, there could be high attrition of FSWs participating in the diaries. To decrease the effect of attrition, regular contact will be maintained between participants and the research team. Finally, as the bio-behavioural surveys are cross-sectional, we will be unable to confer causality. However, we specifically chose these methods as we believe that a cross-sectional approach will give us an understanding of the broader sex worker population. We will apply a mixed-methods approach using findings from the survey coupled with more nuanced and deeper understandings at the individual level from the interviews and diaries. Taken together, and with the findings from the modelling, these methods will allow us to develop an understanding of epidemic pathways resulting from the conflict.

In the current study we have a unique and timely opportunity to understand whether and how conflict and its consequences influence HIV and HCV among FSWs, clients, and the broader population in Ukraine as the conflict unfolds. The mixed method approach used in this study will give complementary insights into the effects of conflict that will provide a stronger evidence basis for attribution than time trends in HIV prevalence alone, and the study will importantly examine explicitly how the nature and practice of sex work is modified by the conflict. Rigorous and context-specific data on HIV and $\mathrm{HCV}$ transmission in the setting of conflict is critical to inform prevention and care services, both currently in the Ukraine and for future conflict response in other settings.

\section{Abbreviations}

CGPH: Centre for Global Public Health; DBS: Dried blood spot; FSWs: Female sex workers; HCV: Hepatitis C virus; IBBS: Integrated Biological and Behavioural Survey; PLHIV: People living with HIV; REB: Research ethics board; UISR: Ukrainian Institute for Social Research after Oleksandr Yaremenko; VPN: Virtual private network

\section{Acknowledgements}

We would like to acknowledge the entire Dynamics Study Team including Leigh McClarty, Francois Cholette, Emma Lee, Lyle McKinnon, Maureen Murney, Nicole Herpai, Sevgi Aral, Ani Shakarishvili, Stephen Moses, Tetiana Bondar, Tatiana Tarasova for their work on this study.

This work is conducted in partnership with the Ukrainian Institute for Social Research after Oleksandr Yaremenko (UISR), the Alliance for Public Health in Ukraine, the Dnipro Oblast AIDS Centre and the Center for Public Health, the Ministry of Health in Ukraine.

\section{Funding}

This study is funded by the Canadian Institutes for Health Research [Funding Reference Number PJT-148876]. This funding source had no role in the design of the study and will not have a role in the collection, analysis or interpretation of the data.

Marissa Becker is supported by a new investigator award from the Canadian Institutes of Health Research; Sharmistha Mishra is supported by a new investigator award from the Canadian Institutes of Health Research and Ontario HIV Treatment Network. James Blanchard, Rob Lorway and Michael Pickles are supported by Canada Research Chairs.
Availability of data and materials

Not applicable.

\section{Authors' contributions}

$M B, S M, R L, J B$ and MP conceived of the study objectives and the study design. $M B$ and $E R$ wrote the first draft of the manuscript, $M B$ refined the versions and SM, RL, MP, EC, EF, LL and SI contributed to the development of the manuscript. DP and OB are the Ukraine site leads on the project and contributed to the development and finalization of the manuscript. EC led the development of the quantitative study tools with input from HM, SM, $M B, M P, E F, D P$ and $O B$ and review by the entire study team. $L L$ and $R L$ developed the qualitative study tools with support from MM. SI led the development of the mapping tools with input from the study team and finalization by SI and MB. PS and EC developed the biological testing protocol. All authors reviewed and approved the final version of the manuscript.

\section{Ethics approval and consent to participate}

Ethical approval was obtained from the Human Research Ethics Board at the University of Manitoba [HS20653(H2017:097)], Canada, the Ethical Review Committee of the Sociological Association of Ukraine, and the Committee on Medical Ethics of the L. Gromashevsky Institute of Epidemiology and Infectious Diseases at the National Academy of Medical Sciences of Ukraine. All participants provided written informed consent. Participants under 16 years of age were considered mature minors and provided consent to take part in the study without consent from their parent or guardian. This was approved by the local ethics committees.

\section{Consent for publication}

Not applicable.

\section{Competing interests}

The authors declare that they have no competing interests.

\section{Publisher's Note}

Springer Nature remains neutral with regard to jurisdictional claims in published maps and institutional affiliations.

\section{Author details}

${ }^{1}$ Centre for Global Public Health, Rady Faculty of Health Sciences, University of Manitoba, R070 Med Rehab Bldg, 771 McDermot Avenue, Winnipeg, Manitoba R3E 0T6, Canada. ${ }^{2}$ Department of Community Health Sciences, University of Manitoba, S113 - 750 Bannatyne Avenue, Winnipeg, Manitoba R3E OW3, Canada. ${ }^{3}$ Ukrainian Institute for Social Research after Oleksandr Yaremenko, 26 Panasa Myrnogo Str., Of. 211, Kyiv 01011, Ukraine. ${ }^{4}$ India Health Action Trust, E17, Ring Road, Defence Colony, New Delhi 110021, India. ${ }^{5}$ University of Toronto, 27 King's College Circle, Toronto, Canada. ${ }^{6} \mathrm{St}$. Michael's Hospital, Li Ka Shing Knowledge Institute, University of Toronto, 209 Victoria St, Toronto, ON M5B 1T8, Canada. ${ }^{7} J C$ Wilt National HIV and Retrovirology Laboratory, 745 Logan Avenue, Winnipeg R3E 3L5, Canada.

Received: 31 March 2019 Accepted: 3 May 2019

Published online: 20 May 2019

\section{References}

1. Quinn J, Stoeva P, Zeleny T, Nanda T, Tomanova A, Bencko V. Public health crisis: the need for primary prevention in failed and fragile states. Cent Eur J Public Health. 2017;25(3):171-6.

2. Internal Displacement Monitoring Centre. Ukraine: translating IDPs' protection into legislative action. Internal Displacement Monitoring Centre, vol. 19; 2016. p. 2016.

3. Julian Coman. On the frontline of Europe's forgotten war in Ukraine. The Guardian. 2017;Sect World News.

4. Mackey TK, Strathdee SA. Responding to the public health consequences of the Ukraine crisis: an opportunity for global health diplomacy. J Int AIDS Soc. 2015;18:19410.

5. Kazatchkine M. Towards a new health diplomacy in eastern Ukraine. Lancet HIV. 2017:4(3):e99-e101.

6. Filippovych S. Impact of armed conflicts and warfare on opioid substitution treatment in Ukraine: responding to emergency needs. Int J Drug Policy. 2015;26(1):3-5. 
7. Vasylyeva TI, Liulchuk M, Friedman SR, Sazonova I, Faria NR, Katzourakis A, et al. Molecular epidemiology reveals the role of war in the spread of HIV in Ukraine. Proc Natl Acad Sci U S A. 2018;115(5):1051-6.

8. Colborne M. Ukrainians battle escalating HIV epidemic. CMAJ. 2017; 189(26):E901-e2.

9. Holt E. Conflict in Ukraine and a ticking bomb of HIV. Lancet HIV. 2018; 5(6):e273-e4

10. Ministry of Health of Ukraine. Ukraine Harmonized Aids Response Progress Report. Kyiv: Ministry of health; 2015.

11. UNAIDS. Country factsheets Ukraine 2017. Geneva: UNAIDS; 2017.

12. Hope VD, Eramova I, Capurro D, Donoghoe MC. Prevalence and estimation of hepatitis $B$ and $C$ infections in the WHO European region: a review of data focusing on the countries outside the European Union and the European free trade association. Epidemiol Infect. 2014;142(2):270-86.

13. Alliance for Public Health. Annual Report. Kyiv: Alliance for Public Health; 2015.

14. Center for Public Health of the Ministry of Health of Ukraine. HIV Infection in Ukraine, Newsletter No. 47. Kyiv: L.V. Gromashevsky Institute of Epidemiology and Infectious Diseases of the National Academy of Medical Sciences of Ukraine; 2017.

15. Vitek CR, Cakalo JI, Kruglov W, Dumchev KV, Salyuk TO, Bozicevic I, et al. Slowing of the HIV epidemic in Ukraine: evidence from case reporting and key population surveys, 2005-2012. PLoS One. 2014;9(9):e103657.

16. Alliance for Public Health. Statistics. Kyiv: Alliance for Public Health; 2017. [HIV Statistics]. Available from: http://aph.org.ua/en/resources/statistics/

17. United Nations High Commissioner for Refugees- Ukraine. UNHCR SubOffice Update Dnipro, March 2017. Dnipro: UNHCR- Ukraine; 2017.

18. Salama P, Dondero TJ. HIV surveillance in complex emergencies. Aids. 2001; 15(Suppl 3):S4-12.

19. Khaw AJ, Salama P, Burkholder B, Dondero TJ. HIV risk and prevention in emergency-affected populations: a review. Disasters. 2000;24(3):181-97.

20. Spiegel PB, Bennedsen AR, Claass J, Bruns L, Patterson N, Yiweza D, et al. Prevalence of HIV infection in conflict-affected and displaced people in seven sub-Saharan African countries: a systematic review. Lancet. 2007; 369(9580):2187-95.

21. Bennett BW, Marshall BD, Gjelsvik A, McGarvey ST, Lurie MN. HIV incidence prior to, during, and after violent conflict in 36 sub-Saharan African nations, 1990-2012: an ecological study. PLoS One. 2015;10(11):e0142343.

22. Bunyasi EW, Coetzee DJ. Relationship between socioeconomic status and HIV infection: findings from a survey in the Free State and Western cape provinces of South Africa. BMJ Open. 2017;7(11):e016232.

23. Wiewel EW, Bocour A, Kersanske LS, Bodach SD, Xia Q, Braunstein SL. The association between neighborhood poverty and HIV diagnoses among males and females in new York City, 2010-2011. Public Health Rep. 2016; 131(2):290-302.

24. Nikolopoulos GK, Fotiou A, Kanavou E, Richardson C, Detsis M, Pharris A, et al. National income inequality and declining GDP growth rates are associated with increases in HIV diagnoses among people who inject drugs in Europe: a panel data analysis. PLoS One. 2015;10(4):e0122367.

25. Pannetier J, Ravalihasy A, Lydie N, Lert F, Desgrees du Lou A. Prevalence and circumstances of forced sex and post-migration HIV acquisition in subSaharan African migrant women in France: an analysis of the ANRSPARCOURS retrospective population-based study. Lancet Public Health. 2018;3(1):e16-23.

26. Durevall D, Lindskog A. Intimate partner violence and HIV in ten subSaharan African countries: what do the demographic and health surveys tell us? Lancet Glob Health. 2015;3(1):e34-43.

27. Olawore O, Tobian AAR, Kagaayi J, Bazaale JM, Nantume B, Kigozi G, et al. Migration and risk of HIV acquisition in Rakai, Uganda: a population-based cohort study. Lancet HIV. 2018;5(4):e181-e9.

28. McGrath N, Eaton JW, Newell ML, Hosegood V. Migration, sexual behaviour, and HIV risk: a general population cohort in rural South Africa. Lancet HIV. 2015;2(6):e252-9.

29. Mock NB, Duale S, Brown LF, Mathys E, O'Maonaigh HC, Abul-Husn NK, et al. Conflict and HIV: a framework for risk assessment to prevent HIV in conflictaffected settings in Africa. Emerg Themes Epidemiol. 2004;1(1):6.

30. USAID. Ukraine - complex emergency fact sheet \#4, fiscal year (Fy) 2018. Kyiv: USAID; 2018

31. UNHCR. Summary of participatory assessments with internally displaced and conflict affected people in Ukraine UNHCR; 2015.
32. lakunchykova OP, Burlaka V. Correlates of HIV and inconsistent condom use among female sex Workers in Ukraine. AIDS Behav. 2017;21(8):2306-15.

33. Elmes J, Skovdal M, Nhongo K, Ward H, Campbell C, Hallett TB, et al. A reconfiguration of the sex trade: how social and structural changes in eastern Zimbabwe left women involved in sex work and transactional sex more vulnerable. PLoS One. 2017;12(2):e0171916.

34. State Statistics Service of Ukraine. Actual Population of Ukraine. Kiev: Ministry of Economic Development and Trade; 2018.

35. Balakirieva O, Bondar T, Loktieva I, Sazonova Y, Sereda Y, Hudik M. Monitoring the behaviour and HIV-infection prevalence among female sex workers as a component of Hiv second generation surveillance. Kyiv: Alliance for Public Health; 2014

36. McClarty L, Balakireva O, Pavlova D, Cheuk E, Nguien N, Pickles M, et al. Estimating Female Sex Workers' Early HIV And Hepatitis C Risk In Dnipro, Ukraine: Implications For Epidemic Control (Transitions Study): Summary Report Of Early Findings. 2018.

37. Emmanuel F, Isac S, Blanchard JF. Using geographical mapping of key vulnerable populations to control the spread of HIV epidemics. Expert Rev Anti-Infect Ther. 2013;11(5):451-3.

38. Emmanuel F, Blanchard J, Zaheer HA, Reza T, Holte-McKenzie M, Team H. The HIV/AIDS surveillance project mapping approach: an innovative approach for mapping and size estimation for groups at a higher risk of HIV in Pakistan. AIDS. 2010;24:S77-84.

39. Emmanuel F, Thompson LH, Salim M, Akhtar N, Reza TE, Hafeez H, et al. The size and distribution of key populations at greater risk of HIV in Pakistan: implications for resource allocation for scaling up HIV prevention programmes. Sex Transm Infect. 2013;89(Suppl 2):ii11-7.

40. Ikpeazu A, Momah-Haruna A, Madu Mari B, Thompson LH, Ogungbemi K, Daniel U, et al. An appraisal of female sex work in Nigeria-implications for designing and scaling up HIV prevention programmes. PLoS One. 2014;9(8):e103619.

41. Odek WO, Githuka GN, Avery L, Njoroge PK, Kasonde L, Gorgens M, et al. Estimating the size of the female sex worker population in Kenya to inform HIV prevention programming. PLoS One. 2014;9(3):e89180.

42. Family Health International/Nepal. Integrated Biological and Behavioural Survey among Female Sex Workers in Kathmandu Valley- Round III JuneAugust 2008. Kathmandu: National Center for AIDS and STD Control; 2008.

43. Ministry of Health. On the organization of the system of Counseling and Testing fo HIV, HCV, HBV and STI. Kyiv: Ministry of Health, Government of Ukraine; 2012

44. Ministry of Health. On improvement of HIV Diagnostics. Kyiv: Ministry of Health; 2010.

45. Volosevich I, Konoplitska T, T. K, al. e. Monitoring the behavior and HIVinfection prevalence among female sex workers clients as a component of HIV second generation epidemiological surveillance: analytical report based on the results of bio-behavioral study 2014. Kyiv: International HIV/AIDS Alliance in Ukraine; 2015.

46. Wang SJ, Salihu M, Rushiti F, Bala L, Modvig J. Survivors of the war in the northern Kosovo: violence exposure, risk factors and public health effects of an ethnic conflict. Confl Heal. 2010:4:11.

47. Hossain M, Zimmerman C, Kiss L, Kone D, Bakayoko-Topolska M, Manan DK, et al. Men's and women's experiences of violence and traumatic events in rural cote d'Ivoire before, during and after a period of armed conflict. BMJ Open. 2014;4(2):e003644.

48. Kothari A, McCutcheon C, Graham ID. Defining integrated knowledge translation and moving forward: a response to recent commentaries. Int $J$ Health Policy Manag. 2017:6(5):299-300.

49. Hankins CA, Friedman SR, Zafar T, Strathdee SA. Transmission and prevention of HIV and sexually transmitted infections in war settings: implications for current and future armed conflicts. Aids. 2002;16(17): 2245-52. 